\title{
Rorty y Derrida en el debate contemporáneo en torno a la superación de la epistemología
}

Víctor Páramo Valero*

\section{Resumen}

El artículo analiza, en primera instancia, la posición de Richard Rorty respecto a la epistemología en La filosofía y el espejo de la naturaleza. Identificamos su concepción de la hermenéutica con lo que se ha dado en llamar «superación de la epistemología». Asumiendo la perspectiva que el pensador norteamericano ha aportado en distintos ensayos sobre la obra de Jacques Derrida, entramos, en segundo lugar, a detallar lo que este último ha defendido sobre las aspiraciones de la filosofía, enmarcando su posición dentro de la crítica nietzscheana a la epistemología. A partir de la perspectiva de ambos autores, extraemos una serie de conclusiones que conciernen al estatus de la epistemología como disciplina filosófica.

\section{Palabras clave}

Epistemología, Rorty, Derrida, superación. 


\title{
Rorty and Derrida in the contemporary debate about the overcoming of the epistemology
}

\begin{abstract}
The paper discusses, first, the position of Richard Rorty about epistemology in Philosophy and the Mirror of Nature. We identify his hermeneutics proposal with what is known as «overcoming epistemology». Assuming the perspective that the American thinker has offered in several essays on the work of Jacques Derrida, we detail, secondly, what the French philosopher has stated about the philosophy and its aspirations, from the Nietzschean critique of epistemology. We extract from the position of both authors a number of conclusions concerning the status of epistemology as a philosophical discipline.
\end{abstract}

\section{Keywords}

Epistemology, Rorty, Derrida, overcoming.

\section{Introducción}

Han sido muy diversas las temáticas que han llevado a pensadores de procedencia un tanto dispar a desembocar en el cuestionamiento del estatus de la filosofía y, en particular, de la epistemología, entendida como aquella disciplina cuyos métodos aspiran a alcanzar un conocimiento que fundamente al resto de los saberes filosóficos, así como a los saberes científicos. En el panorama filosófico contemporáneo la distinción entre saberes teóricos y saberes prácticos parece haberse establecido de forma definitiva; el saber del político no es el saber del científico, ni tampoco el saber del filósofo. Esta disimilitud entre los objetos de conocimiento había sido ya establecida en la filosofía griega, de la mano de Aristóteles ${ }^{1}$. Sin embargo, y de ahí la situación tan diferenciada (que ha conducido a algunos

1 La distinción entre los modos de saber aparece ya en Platón, pero todavía algo difusa, como aclara Serafín Vegas en una nota a pie de página del Teeteto (Madrid: Biblioteca nueva, 2008), a propósito de la agrupación de los tipos de saberes que realiza Teeteto para responder por primera vez en el diálogo a la pregunta y problema clave que allí se tratan: «¿̇Qué es el conocimiento?». La clasificación de los modos de saber se halla en el libro V de la Ética a Nicomaco aristotélica. 
autores a calificarla como "paradójica»²), los saberes se distinguen por la racionalidad a la que se atienen, una racionalidad que ha precipitado a las ciencias a una concepción menguada de la razón ${ }^{3}$ y a la identificación de la epistéme griega con el «saber racional». La consecuencia más inmediata de este planteamiento, que ha ido tomando arraigo tanto en las ciencias formales y experimentales como en la filosofía de la ciencia y la teoría del conocimiento, ha sido la de haber suprimido ciertas formas de saber que en Aristóteles eran plenamente identificados con el lógos.

Al margen de cómo se haya erigido la concepción científica que acabamos de señalar, lo que aquí vamos a discutir está vinculado al modo en que la teoría del conocimiento se ha constituido con base en eso que hoy podemos llamar «explicación» o «justificación racional». Esta acepción es precisamente la que aparece en el Teeteto para tratar de definir en qué consiste el conocimiento, cuya consistencia será cuestionada por el propio Platón.

En el contexto de la epistemología del siglo XX cabe destacar el empuje del célebre artículo de E. Gettier, «Is Justified True Belief Knowledge? $\gg^{4}$, en el que expuso dos casos que suponían una importante objeción a la concepción del conocimiento como «creencia verdadera justificada» y el cual motivó nuevos argumentos a favor y en contra de la aceptación de esta definición. Como seguidamente trataremos de discutir, es posible que este tipo de cuestiones primordiales en la epistemología carezcan de sentido y que, por tanto, la opción meta-epistemológica más acertada deba ser, necesariamente, el abandono de los problemas que dentro de esta disciplina surgen.

A la problemática que acabamos de señalar Richard Rorty dedicó su conocida obra La filosofía y el espejo de naturaleza, la cual constituirá el fundamento de lo que desarrollaremos a partir del primer epígrafe. Ch. Taylor ha tratado con posterioridad de analizar las distintas corrientes que han constituido «la filosofía del fin de

2 Cf. El planteamiento del problema paradójico de la objetividad científica que deja fuera del espacio de la racionalidad a la fundamentación de la moral en Karl-Otto Apel, La trasformación de la filosofía II (Madrid: Taurus, 1986), 345-360.

3 Cf. Max Horkheimer, Crítica de la razón instrumental (Madrid: Trotta, 2002).

4 Edmund Gettier, «Is Justified True Belief Knowledge?», Analysis 23 (1963): 121-123. 
la Filosofía» ${ }^{5}$, en su artículo "La superación de la Epistemología». Allí explica cómo el Racionalismo crítico ha contribuido a continuar el auge que la teoría del conocimiento tuvo con el desarrollo del Empirismo lógico. Las ideas de Taylor son interesantes porque proporcionan una perspectiva que puede contribuir a contextualizar el impacto de Rorty y el contenido del pensamiento que continuará desarrollando a partir del texto mencionado. El filósofo canadiense se pregunta qué es exactamente lo que se está tratando de negar al calificar a la epistemología como un proyecto errado y errante ${ }^{7}$, llegando a la conclusión, que recoge lo expuesto por Rorty, de que se ha tratado de «superar o criticar» ciertas ideas que están en relación directa con una comprensión de aquella disciplina en términos de lo que Rorty identifica como «su enfoque amplio, la entera interpretación representacional del conocimiento y no solo como la fe en el fundacionalismo $»^{8}$.

Además de tratar el pensamiento de Rorty, en este artículo vamos a referirnos a algunas de las importantes ideas que podemos hallar en la obra del filósofo francés Jacques Derrida ${ }^{9}$. El argumento que proponemos desarrollar afirma que puede incluirse al pensamiento de Derrida junto al de Rorty en el contexto de la superación de la epistemología al que hemos aludido ${ }^{10}$. Con ello trataremos de con-

Cf. José Manuel Bermudo, Filosofía política III: asaltos a la razón política (Barcelona: El Serbal 2005), 443.

En Charles Taylor, Argumentos filosóficos (Barcelona: Paidós, 1997).

Ibíd., 20.

Richard Rorty, La filosofía y el espejo de la naturaleza (Madrid: Cátedra, 2010), 23.

El pensamiento con el que hoy identificamos a Derrida tiene estrictamente comienzo con la publicación en 1967 de tres obras que, según Rorty, seguirán siendo las más importantes de Derrida hasta el final de su actividad intelectual: De la Gramatología, La escritura y la diferencia y La voz y el fenómeno. En este trabajo nos ocuparán, fundamentalmente, La diseminación y Espolones. Los estilos de Nietzsche, dos escritos que fueron publicados en 1972 y 1976, respectivamente.

Vicente Sanfélix, en su introducción a Mente y conocimiento (Madrid: Biblioteca Nueva, 2003), 33 75 llama la atención especialmente sobre la obra de Rorty La filosofía y el espejo de la naturaleza para referirse a la «destrucción de la teoría del conocimiento». E. Nájera, en un artículo titulado «El contexto del debate contemporáneo en torno a la superación/recuperación de la epistemología», Daimon. Revista Internacional de Filosofía 51 (2010): 183-198, analiza la obra citada de Rorty, a la que contrapone críticamente las de otros filósofos que han tratado de reconstruir la epistemología en lugar de abandonarla, como es el caso de S. Haack, o el de la meta-epistemología histórica de I. Hacking. Se ocupa también de la propuesta Ch. Taylor, a la que sitúa en la línea de la rortyana (aunque indica algunas importantes diferencias entre ambas). Haack y Hacking han planteado ciertas exigencias a las que tanto el «comunitarismo» como el «neopragmatismo» renuncian. Estas dos últimas posiciones tratan de mostrar el carácter contingente de tales existencias, y afirman que la epistemología como disciplina teórica moderna opera a partir de ciertos presupuestos vinculados 
firmar la interpretación que el propio filósofo norteamericano ha hecho de la obra de Derrida, la cual ha cobrado gran relevancia en la filosofía del siglo XX y en la actualidad sigue presente con gran fuerza.

Examinaremos la posición de Rorty con respecto a la epistemología en la obra citada, donde identificaremos su propuesta hermenéutica con la "superación de la epistemología»(1). Las interpretaciones del pensamiento de Derrida han sido múltiples, e incluso, como ha señalado Rorty, han ido en direcciones opuestas. Aquí trataremos, según hemos indicado, de ceñirnos a la interpretación de la obra de Derrida a la que se adscribe Rorty. Si de realizar un trabajo histórico-filosófico se tratase, lo más conveniente habría sido entrar en primer lugar en lo que Derrida haya podido decir en sus obras, con tal de comprender las razones que ha tenido Rorty para haber atribuido al pensamiento del filósofo francés un carácter como el que veremos. Pero aquí el propósito es otro. No se trata de entrar sin más en los ensayos que Rorty ha dedicado a Derrida y señalar su acierto o su error a la hora de clasificar la obra del pensador francés, sino más bien de haber asumido de forma crítica la perspectiva que Rorty adopta -cuestionando algunos aspectos de la misma- a fin de introducirnos en las propias obras de Derrida, mirando retrospectivamente lo que ha aportado con respecto a la epistemología y sus aspiraciones (2). El objetivo es, pues, hacer ver la consonancia que hay entre Rorty y Derrida en el marco general del problema sobre la legitimación del estatus filosófico de la epistemología.

\footnotetext{
a la idea moral de auto-responsabilidad. La expresión «superación de la Epistemología» constituye, como hemos citado más arriba, el título del primer capítulo de la obra de Ch. Taylor Argumentos filosóficos. En el célebre escrito de R. Carnap «Superación de la metafísica mediante el análisis lógico del lenguaje», el concepto «superación» posee un significado bien diferente al que Heidegger había utilizado en un ensayo titulado «Superación de la metafísica». Sanfélix se refiere precisamente al concepto de «Destrucción» en un sentido no muy distante del que utiliza Heidegger en Ser y tiempo y que, como ha indicado F. Vidarte, se aproxima lo que Derrida ha denominado «Deconstrucción»: el filósofo francés acepta de Heidegger «la tarea de bucear en sentidos olvidados o esquivados a lo largo de la tradición metafísica, en una tarea de Destruktion o Abbau que encontrará, sin embargo, en Derrida, como resultado de la herencia de Nietzsche, un carácter positivo, creativo, afirmativo. Algo así es, de hecho, lo que se ha dado en llamar deconstrucción», Francisco Vidarte y Francisco Rampérez, Filosofías del siglo XX (Madrid: Síntesis, 2005), 260. Cf. Cristina de Peretti, C. «Deconstrucción», en Diccionario de hermenéutica, ed. Andrés Ortiz-Osés y Patxi Lanceros (Bilbao: Universidad de Deusto, 1998).
} 


\title{
1. Hermenéutica y superación de la epistemología en R. Rorty
}

\subsection{La discusión rortyana con la epistemología}

Es difícil evaluar el impacto que Rorty ha ejercido en la filosofía contemporánea a partir de la publicación en 1979 de La filosofía y el espejo de la naturaleza, obra con la que el pensador norteamericano se dio a conocer internacionalmente y donde realizaba un autoanálisis de algunas de las grandes ideas antiguas y modernas en torno al conocimiento humano. La acometida de Rorty trata de desacreditar a la epistemología como disciplina que proporciona los fundamentos de todo conocimiento. En la propuesta que Rorty ofrece hacia el final de la obra citada, en la cual habremos de reparar con más detalle, vemos qué es lo que a su juicio ha de quedar fuera de los límites de la filosofía. La hermenéutica a la que él recurre no tiene que ver con el conocimiento,

\begin{abstract}
no es otra forma de conocer. (...) Es mejor considerarla como otra forma de arreglárselas. Sería mejor para la claridad filosófica que entregáramos la idea de «cognición» a la ciencia predictiva, y dejáramos de preocuparnos por los «métodos cognitivos alternativos». La palabra conocimiento no parecía digna de que se luchara por ella si no fuera por la tradición kantiana según la cual ser filósofo es tener una «teoría del conocimiento», y la tradición platónica de que la acción que no está basada en el conocimiento de las proposiciones es «irracional» ${ }^{11}$.
\end{abstract}

Rorty expone, acudiendo a Descartes, Locke y Kant, cómo la filosofía moderna construyó un proyecto según el cual al aprender más sobre nuestras posibilidades de alcanzar verdades y al reconocer que el camino que debíamos seguir para poder aprenderlo era conocer el funcionamiento de nuestra mente, llegaría a ser, con el tiempo, «bautizado con el nombre de "epistemología"»12. Al adquirir las habilidades necesarias para introducir a la filosofía en el «camino seguro de la ciencia» se la podría conducir a una dimensión a la que la propia ciencia no tendría acceso. Un saber con el que poder fundamentar los métodos, objetivos y desarrollo de la investigación científica, 
sería, finalmente, el más esperado de todos los saberes. Las tesis y argumentaciones que Rorty explica en la primera parte -dedicada a la filosofía de la mente- de la obra citada llevarán en la segunda al problema de la razón, al cual el pensador norteamericano ve todavía en un estado precario en nuestros días, por la influencia kantiana que se ha mantenido en los pensadores más representativos de la teoría social y la teoría del conocimiento. Rorty centra sus esfuerzos exegéticos en la idea, decisiva para él, de la representación en un «espejo interior» de lo que existe fuera de la mente en forma de realidad natural, con el fin de hacer que la comprendamos como el gran error que ha cometido la filosofía, sobre todo por el hecho de que esa realidad a la que se aspiraba mediante el auto-conocimiento no podía estar exenta de una concepción de la razón que, al querer neutralizarse, suprimió artificialmente los elementos circunstanciales que también formaban parte de ella, estableciéndolos como irrelevantes. La «idea del conocimiento humano en cuanto reunión de representaciones en un Espejo de la Naturaleza» ${ }^{13}$ es destruida una vez que la idea de «la Mente» que la precede y de la que ha surgido se viene abajo. De este modo se prescinde del intento de alcanzar una «razón neutral».

Parte de lo que Rorty expone sobre la filosofía de la mente (concretamente, sobre el "problema mente-cuerpo») está relacionado con la teoría del conocimiento ${ }^{14}$, por ejemplo, la crítica a Descartes y la idea de la "capacidad de existir separadamente del cuerpo» ${ }^{15}$, la crítica a las ideas de la teoría lockiana del conocimiento, a la idea de «incorregibilidad» ${ }^{16}$, a la transformación del escepticismo que la Modernidad lleva a cabo ${ }^{17}$ o también $y$, sobre todo, el supuesto de que

13 Ibíd., 122.

14 La obra de Rorty comienza aludiendo a los problemas sobre los que reflexionan los filósofos. "Algunos de ellos se refieren a la diferencia entre los seres humanos y los demás seres, y se cristalizan en preguntas sobre la relación entre la mente y el cuerpo. Otros problemas hacen referencia a la legitimación de las ansias de conocer, y se cristalizan en preguntas sobre los "fundamentos" del conocimiento. Descubrir estos fundamentos es descubrir algo sobre la mente, y al revés», Ibíd., 13.

15 Ibíd., 50.

16 " "Siempre que hacemos un informe incorregible sobre un estado de nosotros mismos, tiene que haber una propiedad que se nos ofrezca y que nos induzca a hacer este informe" -principio vital para la imagen del Espejo de la Naturaleza», Ibíd., 100.

17 «La epistemología del velo-de-ideas que se adueñó de la filosofía en el siglo XVII transformó el escepticismo de una curiosidad académica (escepticismo pirroniano) y una cuestión teológica concreta y local (la autoridad de la Iglesia frente a la del individuo que leía la Escritura) en una tradición cultural. Lo hacía poniendo en pie un nuevo género filosófico -el sistema que vuelve a unir el sujeto y el objeto», Ibíd., 111. 
«hay un problema sobre la mente y el cuerpo» ${ }^{18}$, el cual no deja de estar vinculado a lo que el platonismo y aristotelismo dijeron sobre la «comprensión de los universales», así como a la recuperación -en los albores de la Edad Moderna- de la idea aristotélica de «sustancia». Nos centraremos ahora en su crítica explícita a la teoría del conocimiento moderna y, en particular, a algunos de los elementos que él entiende que han sido centrales para dejar atrás de forma definitiva el proyecto moderno que aspiraba -también desde el análisis de la mente al que hemos aludido- a confirmar algunas «pretensiones de conocimiento y descalificar otras». Con ello Rorty habrá mostrado la superación que ya han realizado los grandes filósofos a los que sitúa como padres del «giro lingüístico» y «giro hermenéutico».

Lo reflejado por la mente había tenido para los pensadores modernos un referente en la naturaleza. Ambas interactuaban sin que se confundieran por completo. La relación entre ellas suscitaba, precisamente, los problemas en torno al conocimiento humano. Para Rorty, lo relevante de las diferentes concepciones que centraban su atención en esa interrelación entre la mente-vidrio y la naturaleza, consiste en que presuponían una determinada función de la filosofía. La obra de Rorty es, ante todo, un ejercicio de reflexión sobre lo que ha sido la filosofía misma. Este rasgo ha continuado presente en algunas de sus obras posteriores, en las que, por ejemplo, discute el papel que la filosofía tiene en la sociedad americana estadounidense. La filosofía en cuanto disciplina se ha considerado «a sí misma como un intento de confirmar o desacreditar las pretensiones de conocimiento que se dan en la ciencia, en la moralidad, en el arte o en la religión ${ }^{19}$. Esta definición que ofrece Rorty al comienzo de su obra es importante por cuanto será la que discuta a lo largo de la misma.

Rorty pretende delimitar el espacio que existe entre la comprensión de la filosofía que se ha mantenido desde la Modernidad y la comprensión que a partir del «giro herméneutico» y el «giro lingüístico» se ha ofrecido. En esta última los presupuestos asumidos en aquélla quedan subvertidos; no se pretende ofrecer una nueva teoría que dé cuenta de los fenómenos sobre los que aquéllos habían tra- 
bajado en el espejo. Para Rorty no es posible elaborar ya una teoría del conocimiento en tanto que, tras el ataque de Sellars al «Mito de lo dado» y el de Quine a los «dogmas del empirismo», la teoría del conocimiento en sí misma ha quedado como una disciplina en bancarrota. El filósofo norteamericano no concluye que sea imposible sin más el conocimiento, sino que trata de restar las connotaciones que le habían atribuido el racionalismo, empirismo, fenomenismo, empirismo lógico, idealismo, idealismo trascendental u otras doctrinas epistemológicas. Rorty introduce una noción de conocimiento sustentada por el pragmatismo, donde no existe la dualidad entre el conocimiento como representación del mundo y el «conocimiento práctico». Tal dualidad había permitido, precisamente, concebir al conocimiento teórico como una reproducción de lo que hay en la «naturaleza».

Lo sorprendente de La filosofía y el espejo de la naturaleza es su insistencia en criticar la idea de un conocimiento trascendental que hable de las propias condiciones de posibilidad del conocimiento. Kant había tratado de dar en la Crítica de la razón pura una nueva perspectiva al "problema» del conocimiento, una perspectiva que asumiese que no puede justificarse el conocimiento apelando a una explicación causal del mismo. A juicio del pensador norteamericano, la respuesta kantiana pretende explicar «desde dentro» aquello que constituye al conocimiento, con lo cual sigue sin salir de los marcos trazados por el empirismo ${ }^{20}$. La idea empirista respecto a la existencia de una "conciencia pre-lingüística ${ }^{21}$, es importante en el contexto de la crítica rortyana que estamos viendo. A propósito de algunos rasgos fundamentales del empirismo y trascendentalismo, Rorty expone cómo la noción de «teoría del conocimiento» es fruto de una confusión que Locke y Kant cometieron cuando, en el caso del primero, se identifica la «justificación» del conocimiento con el funcionamiento fisiológico de la mente, algo que, como hemos indicado, Kant trata de superar, a juicio de Rorty, sin dejar de usar «metáforas causales» e incurriendo también en el error de identificar «predicación (decir

20 Edgar Maraguat, «Apercepción y sistemas causales. A vueltas con la filosofía kantiana de la mente», Ágora 26-1 (2007): 91.

21 La crítica a esta idea es desarrollada por Wilfrid Sellars en Ciencia, percepción y realidad (Madrid: Tecnos, 1971). 
algo de un objeto) y síntesis (unir representaciones en el espacio interior) $»^{22}$. El «conductismo epistemológico» ${ }^{23}$ vendría a superar las confusiones que hay en Locke y Kant mediante el abandono de la idea que subyace a tales errores, a saber, la del «conocimiento como representación».

El equívoco entre la «justificación de las pretensiones de conocimiento y su explicación causal» ${ }^{24}$, esto es, entre lo que de hecho sucede y su explicación acudiendo a conceptos que refieran a procesos psicológicos y fisiológicos, es disipado por el conductismo que Rorty describe, pues, lejos de proponer una explicación histórica sociobiológica o cultural, para el autor norteamericano logra ofrecer una concepción de la verdad en que las connotaciones modernas desaparecen, dando paso a una aceptación de que ella, la verdad, tiene un origen en las prácticas sociales y en las reglas que a través de ellas se estipulan.

La concepción pragmática del conocimiento niega que este sea una representación de la realidad o, más concretamente, una «representación exacta» de la realidad ${ }^{25}$. Lo decisivo en este punto es que Rorty ve que tras la concepción moderna del conocimiento está la idea de que la mente es un espejo que en ocasiones representa la realidad de modo exacto y en ocasiones su reflejo distorsiona la realidad e impide que accedamos a ella. La justificación, a la que nos hemos referido, de las pretensiones de conocimiento mediante una explicación causal del mismo, no es para Rorty sino una idea que nace con Descartes y la estipulación que realizó el filósofo francés de un momento previo e irrefutable que todo saber requiere para ser «seguro». La superación del escepticismo dentro del problema de

Richard Rorty, op. cit., 141.

«Explicar la racionalidad y autoridad epistemológica por referencia a lo que la sociedad nos permite decir, y no lo segundo por lo primero, constituye la esencia de lo que designaré con el nombre de "conductismo epistemológico" (...). La mejor forma de entender esta clase de conductismo es considerarlo como una especie de holismo - pero un holismo que no necesita apuntalamientos metafísicos idealistas-. Afirma que si entendemos las reglas de un juego lingüístico, entendemos todo lo que hay que entender sobre la causas por las que se hacen los movimientos en ese juego lingüístico. (...) Si somos conductistas en este sentido, no se nos ocurrirá invocar ninguna de las tradicionales distinciones kantianas», Ibíd., 165.

24 Ibíd., 19.

25 Para un estudio amplio sobre esta cuestión, cf. Daniel Kalpokas, Richard Rorty y la superación pragmatista de la epistemología (Buenos Aires: Del Signo, 2005). 
la conciencia supone para Rorty el nacimiento de la epistemología como disciplina que se ocupa de la cuestión de la representación y su inconstante exactitud. La idea de la representación que se da en el Espejo (la Mente), desaparece cuando se deja de concebir al conocimiento de acuerdo con las categorías modernas que subyacen a tal concepción ${ }^{26}$. Al no haber ya un «problema» con las representaciones exactas, se disipa también, según Rorty, el acercamiento filosófico a la «la Mente».

A continuación nos adentramos en la propuesta de Rorty con la cual vendría a situar a la filosofía misma en un lugar que queda ya muy lejos de esos problemas que cree haber desentrañado como confusiones y presupuestos en las teorías modernas del conocimiento.

\subsection{La propuesta hermenéutica de Rorty como superación de la epistemología}

Rorty concibe a la hermenéutica como una corriente filosófica forjada en la obra de Heidegger y Gadamer. De ella ha circunscrito una interpretación un tanto singular ligada a la propuesta que ofrece en la última parte de La filosofía y el espejo de la naturaleza, donde culmina su argumentación a favor del abandono de los «problemas» con los que la epistemología ha lidiado desde la Modernidad.

Para Rorty la hermenéutica no es «sucesora», «sustituta» o «COrrectora» de la epistemología. La hermenéutica no nos proporciona algo que para la epistemología moderna había sido imposible alcanzar. En ella se muestra lo que sucede cuando ya no se pretende confrontar otras posiciones, otras teorías. Rorty encauza esta idea a través de una interpretación pragmatista.

Para Rorty la hermenéutica consiste en «una expresión de esperanza de que el espacio cultural dejado por el abandono de la epistemología no llegue a llenarse» ${ }^{27}$. A diferencia de la epistemología, aquella no presupone la idea de que exista un espacio común de

\footnotetext{
26 «Solo cuando el sujeto consciente devino sustancia primera y se identificó la realidad objetiva del ente con su representatividad surgieron muchos de los problemas que la teoría del conocimiento discute», Vicente Sanfélix, op. cit., 57.

Richar Rorty, op. cit., 288.
} 
entendimiento, por ejemplo, entre teorías científicas. La conmensurabilidad de los discursos ha sido una conditio sine qua non del alcance de un fundamento en el camino seguido por la epistemología, por cuanto su búsqueda presupone que el hallazgo, el resultado y el producto mismo del conocimiento es consistente y accesible, como tal, para todo sujeto. Rorty apela al «Conductismo epistemológico» al hacer frente a estas ideas modernas, como ya señalamos. Lo describe como una suerte de holismo -por cuanto en su comprensión del conocimiento no hay un punto donde asentar todo el edificio que constituye-, el cual se contrapone al «absolutismo gnoseológico» al que aspiraba la teoría del conocimiento y que se concretaba «en la presuposición de la conmensurabilidad de todas las creencias y en una concepción universalista de la racionalidad $»^{28}$. La racionalidad para Rorty no es la correspondencia con lo real.

Las connotaciones kantianas que posee el concepto "conocimiento» impiden a Rorty proponer una alternativa a la epistemología que las incluya. Piensa que detrás de esta vinculación de cualquier disciplina filosófica (ética, estética, lógica, ...) con el conocimiento hay una imagen del hombre que la predetermina. Rorty, como Heidegger o Wittgenstein, no abandona la filosofía, sino que la convierte en terapéutica, en el sentido de que a través de ella no se logra obtener «conocimiento» ${ }^{29}$. Abandonar la imagen del hombre que acompaña a la filosofía desde los presocráticos es el objetivo de la hermenéutica convencional o contextualista.

El intento de conseguir la verdad tiene sentido dentro de la imagen clásica del hombre a la que Rorty, apoyándose en Gadamer,

28 Ibíd., 306. En el realismo popperiano pueden hallarse diversos puntos de partida con los que hacer frente, desde una perspectiva que aporta rasgos naturalistas dentro del debate sobre el estatus de las teorías científicas, a algunos de los importantes argumentos de Rorty sobre la cuestión que estamos desarrollando. Cf. Karl Popper, Conocimiento objetivo (Madrid: Tecnos, 2010), 49-130.

29 La recepción rortyana de la filosofía de Heidegger se hace, como la de Wittgenstein, desde la visión pragmatista presente en La filosofía y el espejo de la naturaleza. Rorty dice deber mucho tanto a uno como a otro autor. Ha dedicado textos exclusivamente a ambos (cf., por ejemplo, Richard Rorty, «Wittgenstein, Heidegger y la reificación del lenguaje», en Ensayos sobre Heidegger y otros filósofos contemporáneos. Escritos filosóficos II (Barcelona: Paidós, 1993). Para la recepción del pensamiento de Heidegger en la obra de Rorty cf. Federico Penelas, «Recepciones pragmatistas de Martin Heidegger», Areté 23-1 (2011): 109-124. Para la recepción de Wittgenstein cf. Paul Horwich, «Rorty's Wittgenstein», en Wittgenstein's Philosophical Investigations, ed. Arif Ahmed (Cambridge: Cambridge University Press, 2010), 145-161. 
se refiere. La Bildung (educación, formación, «edificación») es para él un proyecto con el que hallar un modo de expresarse filosóficamente en el que se ha abandonado tal imagen del hombre y las connotaciones a las que está asociado el «conocimiento». Para Rorty, si bien la elevación del estatuto de la teoría del conocimiento hacia el centro de lo que es relevante filosóficamente hay que situarla en Kant, las cuestiones que a ella conciernen proceden de la filosofía griega. La búsqueda de un conocimiento objetivo es para Gadamer (algo que encuentra en Heidegger) un proyecto humano; esto es, uno entre otros muchos posibles. La concepción criticada por Heidegger responde a una posición esencialista, a la que él contrapone otra «existencialista», para la cual el hombre no tiene esencia ni es un ser buscador de esencias. Es una alternativa a la imagen clásica, a la que pone en pie de igualdad con las alternativas de la imagen del hombre que puedan proporcionar otras disciplinas como la literatura ${ }^{30}$.

No podemos tomarnos en serio la noción de «esencia», ni la idea de que la tarea del hombre sea la representación exacta de las esencias ${ }^{31}$.

El gran problema que plantea Rorty a partir de la concepción gadameriana de la Bildung es que no hay modo de argumentar a favor de lo que se desprende de la imagen clásica del hombre y de su culminación con la epistemología moderna. Debido a la inexistencia de un terreno común, no puede calificarse como racional a la ciencia y como irracional a la Bildung. No hay discursos que proporcionen espacios comunes de entendimiento en los cuales rechazar una propuesta y admitir otra, por cuanto el «criterio racional» es incorporado -como también lo es el terreno conmensurable- por una imagen del hombre.

Rorty termina La filosofía y el espejo de la naturaleza afirmando que lo que ha tratado de exponer a lo largo de esta obra no es sino un "prolegómeno» a una historia de la cultura occidental en la que la epistemología constituye un capítulo más. La filosofía, una vez

30 Cf. la alusión de Rorty a la cuestión del valor epistemológico de la literatura ficcional, en Consecuencias del pragmatismo (Madrid: Tecnos, 1996), 202 ss.

31 Richard Rorty, La filosofía y el espejo de la naturaleza, op. cit., 328. 
desacreditada como «saber sin presupuestos» y como salvaguarda de los fundamentos de cualquier otro saber, pasa a formar parte de la «conversación de la Humanidad». Abandonar la teoría del conocimiento es asumir que la filosofía es una participante más en esa conversación.

Un análisis sobre la aportación de Rorty al pensamiento posmoderno ha de cuantificar la valía de la argumentación que realiza al referirse a la hermenéutica como un modo de comprender el conocimiento solamente guiado por la esperanza de llegar a un convencimiento mutuo. La parte dedicada a Kuhn y la filosofía de la ciencia en La filosofía y el espejo de la naturaleza pone de manifiesto cómo establecemos patrones de relevancia para las afirmaciones científicas y criterios que nos permitan saber qué ha de caer del lado de lo que puede ser sometido a una investigación científica. El problema está planteado mediante la asignación de una doble polaridad a la comprensión de lo que se acepta con susceptibilidad de convertirse en conocimiento científico. Como hemos visto, para Rorty la hermenéutica no pretende descubrir un «terreno común», sino que ella es lo que queda tras el rechazo de tal búsqueda.

Debemos en este punto comenzar a valorar la crítica de Rorty desde la perspectiva de lo que aquí hemos denominado «superación». «Superar» la epistemología no significa en el contexto rortyano tratar de dejar atrás sin más algo que se entiende como residual, como algo que alcanzó un momento esplendor dentro de la filosofía y que en la actualidad carece de vigencia. Para Rorty, la superación de la epistemología no tiene su razón de ser en que esta haya sido sin más un saber cuyos supuestos eran erróneos. La tentativa de dar con una respuesta adecuada a los «problemas» a los que debe hacer frente aquel filósofo que se haya propuesto resolver definitivamente la relación entre la mente y el conocimiento, el lenguaje y el conocimiento, o la filosofía misma y el conocimiento, puede consistir a la vez en hacerse cargo de las muy diversas maneras que ha habido de plantear tales problemas. Antes que introducirse en ellos y pensar con las formas que requieren para poder ser completados por una línea demarcadora que los contenga dentro una lógica de supuestos, debemos tomar en cuenta ideas como la de que en todo acontecer hay una precomprensión. 
La búsqueda de un saber que sirva de base y fundamento de las ciencias -búsqueda que comienza con la asimilación kantiana de la distinción (realizada por Descartes) entre ciencia y filosofía- ha permanecido vigente en la filosofía de Russell y del positivismo lógico. La argumentación de Rorty no está dirigida únicamente a criticar la concepción que Kant ofrece de filosofía y de los problemas filosófi$\cos ^{32}$, sino también -y acaso sea esto lo que permite entender la forja de su propia propuesta hermenéutica-a desvelar las preconcepciones presentes en el modo en que los filósofos modernos resolvieron las dificultades que suscitaba la comprensión del conocimiento humano. El problema que reside en la idea de que la epistemología resulta ser la disciplina que trata de encontrar las bases del conocimiento que está en juego en el resto de saberes filosóficos y científicos consiste en que la investigación que se requiere para llegar a tales fundamentos encubre una concepción y estructuración de «lo real» bajo formas que, al salir a la luz, se descubren como presupuestos sobre los cuales no cabe argumentar a favor o en contra. No hay, pues, que seguir tratando de acometer un acercamiento a «lo real», a eso real que no es otra cosa que lo reflejado en el espejo; el espejo y la naturaleza son en sí mismos (y así cabe comprenderlo en La filosofía y el espejo de la naturaleza) metáforas de las Rorty quiere desprenderse.

\section{Jacques Derrida y la superación rortyana de la epistemología}

\subsection{La Différance y la crítica a la metafísica de la presencia}

A partir de los elementos de la filosofía de Rorty que hemos visto en el primer apartado, plantearemos ahora la perspectiva que vamos a adoptar a la hora de entrar en algunas de las cuestiones del pensamiento de Derrida que, a nuestro juicio, cobran relevancia en el contexto del debate contemporáneo en torno a la superación de la epistemología.

32 Ibíd., 152. Rorty reitera en Filosofía y futuro que el modo de pensar de Wittgenstein, Sellars y Davidson ha contribuido a alcanzar «lo que los idealistas alemanes intentaron conseguir en vano: podrían convencernos para que dejemos de discutir pseudo-problemas tediosos acerca de la relación entre sujeto y objeto y entre apariencia y realidad. (...) Pueden contribuir a que la filosofía vuelva a encontrar el camino hegeliano, historicista y romántico, que tanto los neokantianos del siglo XIX como los fenomenólogos husserlianos y los fundadores de la filosofía analítica intentaron cerrar», Richard Rorty, Filosofía y futuro (Barcelona: Gedisa, 2008), 75. 
Rorty ha escrito varios ensayos sobre Derrida ${ }^{33}$, al que ha atribuido un pensamiento en la línea de lo que defiende en La filosofía y el espejo de la naturaleza y en otras obras posteriores. Si nos dejamos guiar por el pensamiento de Derrida y Rorty, llegaremos a la convicción de que la epistemología, entendida como (a) un saber que se articula sin precomprensión alguna desde la cual indagar el conocimiento y como (b) un saber que tiene en cuenta únicamente la perspectiva cognitiva del modelo sujeto-objeto, es hoy una disciplina filosófica que, debido a los múltiples argumentos ofrecidos en su contra, no tiene sentido seguir acometiendo ${ }^{34}$.

Nietzsche había criticado el concepto platónico de lógos por su vinculación con el concepto de verdad (el propio concepto de metáfora posee connotaciones negativas ${ }^{35}$ ). Para Derrida tal concepto se encuentra ante un abismo, se halla ante su inminente evanescencia en un permanente «tambaleo» que hace saltar las coyunturas con las que se había tratado de ocultar el devenir, lo sensible. La «huella», la «différance» ${ }^{36}$, es la que determina el concepto de verdad que

33 Entre los más relevantes: «De la teoría ironista a las alusiones privadas: Derrida», Contingencia, ironía y solidaridad (Barcelona: Paidós, 1991); «Derrida, Habermas y la función de la filosofía», Filosofía y futuro, op. cit; «żEs Derrida un filósofo trascendental?», Ensayos sobre Heidegger y otros filósofos contemporáneos. Escritos filosóficos II, op. cit.; «Deconstrucción y circunvención», Ensayos sobre Heidegger y otros filósofos contemporáneos. Escritos filosóficos II, op. cit.; «Notas sobre deconstrucción y pragmatismo», en Deconstrucción y pragmatismo, ed. Chantal Mouffe (Buenos Aires: Paidós, 1998); «Derrida: la filosofía como arte de escribir», Consecuencias del pragmatismo, op. cit. Algunos autores como J. Habermas han tratado de ofrecer una trasformación de la filosofía kantiana, incorporando las críticas hegelianas sin dejar de aspirar a un conocimiento válido universalmente (intersubjetivamente). El propio Rorty ha hecho referencia al pensamiento de Habermas en varios escritos (y también en sus cursos; cf. Richard Rorty, Filosofía y futuro, op. cit., 158), haciendo hincapié, no obstante, en que si bien en Habermas el «mundo de la vida construido según la teoría de la comunicación se ha liberado de "las hipotecas de la filosofía trascendental" y que "en la razón comunicativa no resucita de nuevo el purismo de la razón pura", no tiene intenciones de desasociar la "razón comunicativa" del ideal de "validez universal"», Ibíd., 28.

35 Friedrich Nietzsche, Crepúsculo de los ídolos (Madrid: Alianza, 1998).

36 Différance es un neologismo con el que Derrida, como explica en «Différánce», evoca aquello que está bajo la lógica del nombre y la representación y cuya significación se extiende hasta diseminarse. Cf. Márgenes de la filosofía (Madrid: Cátedra, 1998). Como veremos en el caso de «La farmacia de Platón», Derrida se distancia de lo que él denomina «logofonocentrismo» (cuyo origen sitúa en Sócrates) a través de la idea de que no hay prevalencia entre lo oral y lo escrito. Derrida sostiene que «el funcionamiento de un signo no se basa en que remita a una presencia plena, a una intuición plenamente presente a sí misma, sino en que lo habita la ausencia, ya que debe seguir significando en ausencia de emisor, receptor, referencia, intención». María E. Zarzo Durá, «Jacques Derrida: ontología y lingüística», Cuaderno de materiales. Filosofía y ciencias humanas 23 (2011): 790. Esta idea es introducida por Derrida ya en De la gramatología (Madrid: Siglo XXI, 1986, primera parte) y es uno de los puntos de partida que nos permitirán entender la concepción que mantiene Rorty de Derrida. 
implica al concepto de signo ${ }^{37}$, consecuencia del "necesario» destierro del proceder filosófico. Con esta idea Derrida trata de sacar a la luz la engañosa historia del concepto mismo de concepto. Hay aquí una vinculación directa entre la preocupación de la «escritura nietzscheana» respecto a la «metafísica de la presencia» (y la «historia de la verdad») y entre algunos de los puntos esenciales de la obra derrideana de los que nos vamos a ocupar.

La diferencia es aquello que la lógica de la representación presupone pero que ella misma no puede «representar». No puede representarse lo que posibilita la representación. La metafísica de la presencia no puede pensar lo que la hace posible ${ }^{38}$. El signo que representa a un objeto puede ser a su vez representado, pero lo que no puede representarse es lo que hace posible la representación, a saber, la diferencia.

Entre el signo y el referente hay una diferencia como retardo, demora: hay una brecha temporal entre el objeto representado y lo que lo representa. Lo que posibilita esa brecha no puede ser nombrado. Différance es el «no-nombre» que nombra sin nombrar a lo que hace posible la nominación; el no-nombre différance «nombra» a la diferencia como condición de posibilidad. Différance es el neografismo que «nombra» a las dos condiciones de posibilidad señaladas: diferencia como distinción, divergencia entre el objeto y el signo; y diferencia como dilación ${ }^{39}$.

37 Según Derrida, el concepto de signo se tambalea porque «la verdad solo podrá ser determinada a partir de la différance», Cf. Cristina de Peretti, Jacques Derrida. Texto y Deconstrucción (Barcelona: Anthropos, 1989), 95. Para De Peretti, esta idea derrideana está vinculada a lo que sobre Nietzsche desarrolla el filósofo francés en Espolones. Los estilos de Nietzsche, en relación a la ligazón que traza el filósofo alemán entre la verdad y la mujer: «no hay esencia de la mujer porque la mujer se aleja de sí misma. Absorbe, rodea de un velo por el fondo, sin fin, sin fondo, toda esencialidad, toda identidad, toda propiedad. Cegado aquí el discurso filosófico zozobra -se precipita a su perdición-. No hay verdad de la mujer pero es porque esa distancia abismal de la verdad, esa no-verdad, es la "verdad". Mujer es un nombre de esta no-verdad de la verdad", Ibíd., 96.

38 Jacques Derrida, De la gramatología, op. cit., 19.

39 ¿En qué medida la concepción del lenguaje de Derrida que se deriva de la acuñación del «noconcepto» différance se aleja de la tradición sustancialista que rechaza -junto a Saussure- en la primera parte de De la gramatología y se aproxima a una pragmatista? El propio Rorty ha dedicado un artículo a la cuestión. Cf. "Notas sobre deconstrucción y pragmatismo», en Deconstrucción y pragmatismo, op. cit. Para un análisis de la relación entre el pragmatismo y la "ciencia de la escritura» derrideana, cf. Jolán Orbán, «Pragrammatology: Derrida's Pragmatism, Rorty's Deconstruction», así como la respuesta del propio Rorty a la autora «Reply to Jolán Orbán», en En The Philosophy of Richard Rorty, ed. Randall E. Auxier y Lewis E. Hahn (Chicago: Open Court, 2010). 
El análisis que ofrece Derrida en Espolones. Los estilos de Nietzsche surge a propósito de lo que Nietzsche expone al principio de Más allá del bien y del mal: «...suponiendo que la verdad sea mujer -¿̇cómo? ¿̇no está justificada la sospecha de que todos los filósofos, en la medida en que han sido dogmáticos, han entendido poco de mujeres? $\gg^{40}$. El problema de la verdad es inherente al desarrollo del platonismo, si entendemos por "platonismo» a la filosofía que toma como punto de referencia a Platón. El problema de la representación es el problema planteado por el platonismo tras haber cuestionado que la realidad sensible sea la auténtica realidad, introduciendo así, necesariamente, una dualidad en la realidad, dualidad que se articula entre dos polos opuestos; el referente de la representación, que es aquello de lo que cualquier aparecer en el mundo sensible es copia suya, constituyendo esta el otro extremo ${ }^{41}$.

En el escrito citado de Derrida, la cuestión del «atractivo», del «tener-que-conquistar», de la aspiración suprema «negadaprometida», articula los "estilos de Nietzsche». La concepción derrideana de la verdad se formula a partir de la determinación de esos mismos estilos. Los «espolones de Nietzsche» son aquellas zonas del texto nietzscheano a las que únicamente se accede mediante la comprensión del estilo. Con tal comprensión llegamos a una penetración más profunda (la única) del aforismo nietzscheano -un aforismo fantasmagórico del cual Derrida no deja de «sacar punta», una punta que es el propio espolón-. El despuntar del espolón en Nietzsche es la cooperación del concepto y la metáfora para acabar por des(con)-figurar al propio concepto.

La «distancia» a la que alude Derrida, compone la principal relación entre el filósofo y la verdad. La filosofía estiliza, encubre la «materia $»^{42}$, dejándola marcada, sellada; le atribuye una forma (perpetua), y quizá lo haga para reducirla, incluso para "protegerse de ella». La mantiene a «distancia». La filosofía, entonces, se esconde, se vela (velar, lethes), se reprime a sí misma (va aguardando - acumulando «resentimiento»). ¿Qué la cubre y por qué se oculta? ¿Qué

40 Friedrich Nietzsche, Más allá del bien y del mal (Madrid: Orbis, 1983), Prólogo.

41 Cristina de Peretti, Jacques Derrida. Texto y Deconstrucción, op. cit., 177.

42 Jacques Derrida, Espolones. Los estilos de Nietzsche (Valencia: Pre-textos, 1981), 13. 
en-cubre? El «goce» del ocultamiento nos lo proporciona la «lengua, con tal de que no se articule». Para acercar la cuestión de la mujer a este gesto filosófico, iremos directamente a «las mujeres y su operación a distancia (ihre Wirkung in die Ferne)»»3. Es la «seducción» de la mujer la que opera a -y en- esa distancia.

La verdad como mujer o como el movimiento del velo (Schleir, del pudor femenino $)^{44}$.

«Operar a distancia» consiste en mantener un atractivo, ejercer una fuerza de atracción. Es la mujer la que opera a distancia; la mujer es la verdad, y la verdad no es otra cosa que la invención del filósofo, su autoestablecimiento de la distancia; su autovelamiento como «atractivo».

Derrida incide en que la radicalidad del planteamiento nietzscheano consiste en que su análisis genealógico ha permitido exponer por qué el post-kantismo no responde todavía a las expectativas a las que un completo abandono del idealismo y platonismo conducirían. La supresión y el cierre absoluto de los esquemas sobre los que se ha levantado la filosofía misma darían lugar a una nueva concepción de la «vida». Este término, que para Nietzsche no recoge ni la esencia ni la existencia, ya que esta dualidad se cerraría también al derrumbar el resto del «mundo aparente» que queda tras la supresión del «mundo inteligible», no pretende ser una «representación», pues este «concepto» estaría todavía bajo la lógica de la representación que subyace a la jerarquía entre el «mundo verdadero» y el «mundo aparente» que Nietzsche quiere evitar. Pretende ser la mostración de ella misma tal cual es. Este intento de evadir la idea de representación que procede del esquema platónico, ha formado parte de la crítica derrideana a la metafísica de la presencia.

El objeto de la crítica derrideana en obras como La diseminación lo constituyen algunas de las nociones cruciales de la epistemología y la metafísica nacida con Platón. Derrida afirma en «La farmacia de Platón», evocando al Sócrates de los Diálogos, que «la verdad de la 
escritura, es decir, la no-verdad, no podemos descubrirla en nosotros mismos $»^{45}$. Antes de expresar estas palabras había dicho, refiriéndose a lo que Sócrates expresa sobre la logografía en Fedro 257c, que

escribiendo no se dice, no diría y sin duda no pensaría nunca de verdad, el autor del discurso ha acampado ya en la postura del sofista: el hombre de la no-presencia y la no-verdad. La escritura es, pues, ya escenificación. La incompatibilidad de lo escrito y de lo verdadero... ${ }^{46}$.

Estas ideas constituyen el punto de partida de la concepción derrideana de la «metafísica de la presencia». El concepto de «logofonocentismo» podría ser de utilidad para comparar la hermenéutica rortyiana y el textualismo derridiano, en la medida en que ambos han contribuido, estrechamente, a dar una «comprensión» (en el sentido de Gadamer) de la historia de la filosofía occidental que no puede dejar de situar a Sócrates como su eje central. Sócrates es el «padre del lógos»»7 .

La filosofía derridiana no aspira a desvelar los «márgenes de la filosofía»; pretende hundirse y perderse en ellos, buscando aquello que se ha excluido en el camino que se recorre hasta hallar un supuesto resultado. El desbordamiento que tiene la etapa inicial de Derrida puede hallarse en la publicación de De la Gramatología, La voz y el fenómeno y La escritura y la diferencia ${ }^{48}$.

La «huella», la «différance», el «fármaco», el «suplemento», la «archi-escritura», la «deconstrucción», exigen un tratamiento temático que desborde la "presencia», el propio pensamiento de la presencia, que exceda la presentación fenoménica, una escisión que desborde cualquier posición o exposición, «el tema y el sistema» ${ }^{49}$. El «pensamiento de la différance» permite percibir la mínima diferencia que debe darse para distinguir entre la cosa y la salida a la luz (la fenomenicidad) de la cosa misma. La difícil tarea de presentar lo

45 Jacques Derrida, «La farmacia de Platón», La Diseminación (Madrid: Fundamentos, 1975), 109.

$46 \quad$ Ibíd., 99.

47 Ibíd., 110.

48 Rorty indica que el pensamiento que Derrida ha desarrollado contiene varias etapas claramente divisibles. La primera correspondería con la «profesionalización» o «capacitación» filosófica. A partir de la publicación de las tres obras citadas, Derrida se volvería «más excéntrico, más personal y más original».

49 Cf. el Prólogo de Derrida a Cristina de Peretti, Jacques Derrida. Texto y Deconstrucción, op. cit., 11. 
irrepresentable no deja de respetar «lo intratable, y esta es una forma poco corriente de respeto ${ }^{50}$. Este específico respeto exige dejar de hacerse cargo de la "coagulación del concepto», y, oponerle (en un sentido que conseguiría dejar fuera de su coherencia toda clase de oposiciones), «el juego diseminado del texto».

La explicación del mundo con base en un modelo representativo y a las categorías mediante las cuales se articula su función cognitiva no puede escapar a la «metafísica de la presencia». Lo que está más allá de lo decible no es lo que puede aventurar un modo de ausentarse de la presencialidad exigida de algo (la condición impuesta para poder conocerlo). Se trata de no continuar exigiendo las «vías» por las que accedemos a un conocimiento de una cosa-que-está-ahí-presente. El intento de ver qué queda «más allá» de los discursos representativos seguiría dentro del «discurso representativo tradicional». Lo que recibimos a través de un discurso representativo contiene una lógica que es necesario romper si entendemos que la representación ya no ha de formar parte de nuestro «decir». Pero este «decir» tendrá que perecer. Sustraerse a lo que todo discurso trasmite (como representación) implica no atender ya a lo que escapa al sistema representacional en su funcionamiento mismo. El problema consiste, según señala Derrida, en que esto es imposible; imposible para una tradición filosófica «logo-fono-céntrica». Cuando excluimos el sistema de la representación como tal y tratamos de ver lo que hay más allá lo que queda fuera de él, tal sistema habita asediantemente.

¿Cómo dejar abierto un espacio a lo que es indecible, a lo que no es representable, si lo que en este hay lo conocemos a través de la representación? El filósofo francés se ocupa en La diseminación de las oposiciones como «padre» e «hijo», «sol» y «penumbra», «intuición» y «razonamiento», oposiciones que la tradición filosófica desde Sócrates ha tenido como neutrales. Sin salir del sistema de la representación puede verse lo que lo sustenta, puede verse lo que soporta la tensión entre conceptos contrapuestos. Tal tensión es concebida como el producto de un «tambaleo», esto es, como el concebir algo y a partir de ahí hacer «vibrar» la estructura que posee para hacer «accesible» algo que lo diferencie. La polaridad entre un concepto y 
otro -por ejemplo, «lejanía» y «distancia»- no es natural a la propia contradicción que hay entre ellos; esa contradicción es producto de algo: de una jerarquización a la que, a su vez, se ha llegado por medio de una «identificación excluyente».

El planteamiento derridiano de la «escritura» como «huella», «archi-escritura», «différance», «fármaco», «diseminación» ${ }^{51}$, etc., intenta seguir los pasos de Nietzsche, pero desde una perspectiva tanto o más radical que la nietzscheana. Derrida trata de «superar» la fenomenicidad, la presencia, la presentación, a través del rastro de la huella. "Deconstruir» significa perseguir la «huella» sin asumir que está ahí o, dicho de otro modo, asumiendo que lo que ahí está no tiene necesariamente un carácter re-presentativo.

\subsection{Derrida y la superación de la epistemología}

En El crepúsculo de los ídolos Nietzsche expresa la imposibilidad de acabar con la jerarquización de los conceptos como «verdad»o «inteligibilidad» si no es por medio de la ruptura con sus opuestos: se trata de acabar con el concepto de «falsedad» por medio de un movimiento alegórico que ponga de manifiesto -sin caer en la imposición que conlleva toda presencialidad- que su asociación a un «mundo sensible» no es más que una referencia a $-\mathrm{y}$, al mismo tiempo, un apoyo en- el «mundo inteligible». La pérdida «irremediable, irreparable, de las categorías de presencia y de totalización del pensamiento metafísico ${ }^{52}$ adviene en Nietzsche desde un enfoque que afirma que situarse más allá de lo verdadero implica abandonar también lo falso. Derrida radicaliza dicho enfoque.

Como vimos, para Rorty la epistemología no puede situarse a sí misma en el centro neurálgico de todas las ciencias. Tampoco puede ser si quiera una disciplina más entre las distintas modalidades filosóficas. La filosofía moral pierde asimismo toda aspiración a fundamentar normas y valores en un orden que vaya más allá de lo que la

\footnotetext{
51 Para Derrida la «diseminación» designa una «operación» en la que se juega con los múltiples sentidos que un término posee; esa pluralidad no es únicamente polisemia, sino que realiza asimismo un poner en marcha de modo indefinido los «semas» o «significaciones» entre las «disciplinas». Este movimiento circular lo ejerce hasta que la propia noción de «sentido» («sentido verdadero») se dispersa en infinitas direcciones, y, con ello, se imposibilita que esta noción sirva ya de sustento a los discursos racionales.

Cristina de Peretti, Jacques Derrida. Texto y Deconstrucción, op. cit., 90.
} 
contingencia puede ofrecer; no hay una dimensión trascendental en la que poder asentar o justificar la bondad o el virtuosismo de nuestras acciones. Todas ellas dependen de lo que de modo convencional se ha establecido como válido; a partir de esto, pueden tener una mayor o menor extensión, pueden ser más o menos compartidas. «Lo único que puede desplazar a un mundo intelectual es otro mundo intelectual $\aleph^{53}$.

De ahí que las aspiraciones a alcanzar una comunicación entre individuos que pertenecen a mundos culturales distintos no puedan cumplirse al modo en que lo han propuesto algunos de los filósofos neotrascendentalistas. La validez normativo-comunicativa no se logra a través de la fundamentación previa de esas mediaciones gracias a las cuales es posible una moral. El concepto de «validez» pierde su sentido y, tanto más, el intento de hacer universal esa moral que tan solo encontramos en nuestra inmediatez y a la que podemos tomar, en el mejor de los casos, como una moral válida para el lugar en el que nos encontramos y desarrollamos nuestra existencia.

La idea de que existe un «terreno común» sobre el cual poder construir una argumentación más "crítica», férrea, "verdadera» que otra, es para Rorty tan absurda como la de que Derrida haya tratado de ofrecer una tal clase de argumentos contra el «logofonocentrismo». Aunque el filósofo francés haya tratado de hacer ver cómo Platón y el platonismo ha tomado los principios dialógicos de la Mayéutica socrática y con ellos haya erigido al lógos como el «padre», esto no debe hacernos pensar que lo que Derrida ha acometido ha sido una «argumentación», un «contraataque», una defensa de otro modo de concebir las cosas que mantiene esa referencia a un terreno común. Por el contrario, lo que se ha ofrecido no ha venido a sustituir a lo anterior sino a «invertirlo» (en el sentido nietzscheano). Es decir, no ha

53 Richard Rorty, Ensayos sobre Heidegger y otros filósofos contemporáneos. Escritos filosóficos II, op. cit., 180. La cita está extraída de un pasaje del texto muy sugerente: «Desde mi punto de vista, lo único que puede desplazar a un mundo intelectual es otro mundo intelectual -una nueva alternativa, en vez de un argumento contra una alternativa antigua-. La idea de que existe algún terreno neutral sobre el que elevar un argumento contra algo tan grande como el "logocentrismo" me resulta una alucinación logocéntrica más. No creo que las demostraciones de "incoherencia interna" o de "relaciones de presuposición" sirvan mucho para librarnos de las ideas o instituciones antiguas y malas. (...) Considero que la refutación es signo de falta de originalidad, y aprecio demasiado la originalidad de Derrida para elogiarle en estos términos. Por ello considero poco útil, para leerle o examinar su obra, la noción de "argumentación rigurosa" ». 
desestructurado sin más el edificio filosófico con el que se ha topado, no ha tratado escapar al «sistema de la representación», pues el filósofo francés ha considerado que no hay un «afuera de la representación».

Allí donde Platón habría trazado un puente desde la representación de las Ideas a las Ideas mismas, Derrida no "contrapone» otra «teoría» que "argumente en favor de» otro modo de concebir el conocimiento. Lo que encontramos en algunos de los autores del siglo XX que, a su pesar, han dedicado muchas páginas a la epistemología, no es ya una crítica contra algo que ellos conciben como problemas de la realidad, problemas que existen por sí mismos y que cabe discutirlos al margen del diálogo (público o privado) que se lleva a cabo para expresarlos. El caso de Rorty debe catalogarse como un modelo de filosofía postanalítica.

El capítulo cuarto de La filosofía y el espejo de la naturaleza-el más importante de la obra, según el propio Rorty ${ }^{54}$ - se dedica a la idea ya mencionada de las «representaciones privilegiadas», idea forjada en el seno de la epistemología empirista de Locke y Hume. Esta idea llega hasta Russell y Carnap ${ }^{55}$ y es la que Sellars desdibuja en «El empirismo y la filosofía de la mente» y Quine en «Dos dogmas del empirismo». Rorty dedica aquel capítulo a «defender a Sellars y a Quine», a mostrar la importancia del ataque del primero a «todo el marco de referencia de lo dado» y la crítica del segundo a la distinción necesario-contingente ${ }^{56}$. En la última sección de ese capítulo se incluye una referencia a Donald Davidson ${ }^{57}$, en cuyo planteamiento algunos autores han encontrado huellas derrideanas ${ }^{58}$, aunque es en el capítulo sexto de la obra donde el filósofo norteamericano aborda el contenido de dos trabajos fundamentales de Davidson: «De la idea misma de un esquema conceptual» y «Verdad y significado» ${ }^{59}$.

\footnotetext{
54 Richard Rorty, La filosofía y el espejo de la naturaleza, op. cit., 19.

55 Ibíd., 169.

56 Ibíd., 161.

57 Cf. Ibíd., 192.

58 Cf. Samuel Wheeler, «Davidson as Derridean: Analytic Philosophy as Deconstruction», Cardozo Law Review 27-2 (2005): 567-585.

59 Ambos trabajos fueron publicados, respectivamente, en Proceedings of the American Philosphical Association 47 (1973): 5-20 y Synthese 17 (1967): 304-323. La contribución que supusieron ambos ensayos en el ámbito de lo que Rorty denomina filosofía "postanalítica» es similar a la del ensayo de Sellars «El empirismo y la filosofía de la mente», en Ciencia, percepción y realidad, op. cit.
} 
Al traer a colación esos dos escritos de Davidson queremos señalar un punto central de la concepción del funcionamiento del lenguaje que en ellos expone, concepción a la que Rorty concede especial importancia y que posee ciertas semejanzas con la de Derrida en lo concerniente a la erradicación de la idea de que existe una «conciencia pre-lingüística» ${ }^{60}$. Según Davidson, la propia cuestión de «cómo funciona el lenguaje» no posee vinculación alguna con la de «cómo funciona el conocimiento ${ }^{61}$. La de Davidson es, como la de Derrida, una concepción «des-epistemologizada» ${ }^{62}$ del lenguaje. El siguiente fragmento de «De la idea misma de un esquema conceptual» nos da las claves para entender el tipo de vinculación que puede trazarse entre la superación derrideana de la epistemología y la que, según Rorty, se deriva de los argumentos de Davidson:

No hemos encontrado ninguna base inteligible que nos permita decir que los esquemas [conceptuales] son diferentes. Sería igualmente erróneo proclamar la gran noticia de que toda la humanidad -todos los hablantes de un idioma, al menos- tiene una ontología y un esquema comunes. Si no podemos decir de forma inteligible que los esquemas son diferentes, tampoco podemos decir de forma inteligible que lo sea uno. (...) Dado el dogma de un dualismo de esquema y realidad, conseguimos una realidad conceptual y una verdad relativa a un esquema. (...) Al abandonar el dualismo de esquema y mundo, no renunciamos al mundo, sino que restablecemos el contacto no mediado con los objetos conocidos ${ }^{63}$.

Rorty indica que el capítulo que dedica en Filosofía y futuro a Derrida y a Habermas («Habermas, Derrida y las funciones de la fi-

60 El análisis que Derrida realiza del Ensayo sobre el origen de las lenguas de Rousseau constituye una monumental crítica a la idea de que la fuente del habla (y, por tanto, de la escritura) es la "presencia del yo consigo», piedra de toque del «logocentrismo» en todas sus formas. Cf. Derrida, De la gramatología, op. cit., 180 y ss.

61 Richard Rorty, La filosofía y el espejo de la naturaleza, op. cit., 239.

62 Ibíd., 240.

63 Donald Davidson, «De la idea misma de un esquema conceptual», en De la verdad y de la interpretación (Barcelona: Gedisa, 1990), 198. En este fragmento -que se incluye en un largo pasaje que Rorty (cf. La filosofía y el espejo de la naturaleza, op. cit., 283) -, Davidson expone las conclusiones del argumento que desarrolla en el trabajo citado. Piensa que la idea de «esquema conceptual», que adquiere su configuración esencial en la Crítica de la razón pura de Kant (la dualidad entre intuiciones puras y categorías, entre sensibilidad y entendimiento), es una falacia. Su crítica a la distinción entre esquema y contenido comienza por descartar el relativismo conceptual. Véase el argumento de Davidson en «De la idea misma de un esquema conceptual», op. cit., 195 y ss. 
losofía»), en lo concerniente a su comprensión y posición respecto al pensamiento derridiano, es una extensión o una parte más de lo que había tratado en Contingencia, ironía y solidaridad. En esta última obra Rorty establece una distinción que reaparece a lo largo de la misma y a la que recurre con el fin de establecer qué vías ha seguido para llegar a denominar a Derrida como un filósofo ironista y de «alusiones privadas». Rorty dedica varias páginas a La Carte postale de Derrida, a la que califica como uno de los escritos más importantes de la filosofía contemporánea. Discutiendo lo que el filósofo francés expone «enfrentándose» a teorías del lenguaje que han tratado de solucionar problemas como las paradojas autorreferenciales, el pensador norteamericano concluye afirmando que la distinción entre lo que corresponde a la filosofía y lo que corresponde a la literatura no es algo que quienes escriben obras como La Carte postale aspiren a establecer. Estas obras nos permiten ver que los criterios de los que nos servimos para clasificar, analizar y comprenderlas no han sido predefinidos.

Solo los metafísicos piensan que los criterios y los géneros existentes agotan el reino de la posibilidad. Los ironistas continúan ampliándolo ${ }^{64}$.

\section{Conclusiones}

1. Vimos en el primer apartado que Rorty piensa que no cabe seguir tratando de argumentar a favor de una u otra posición ni tampoco seguir buscando fundamentos válidos universalmente. Señala, asimismo, que cuando se intenta dar cumplimiento a una de estas dos metas no se ha dejado de lado la convicción de que hay un terreno común en el que puede introducirse o extraerse algo que no sea sometible a una discusión posterior. Las ideas que hemos desarrollado en el primer apartado nos han permitido hacer ver el sentido de la propuesta rortyana de «superación» de la epistemología. Rorty hace valer una nueva metodología filosófica al centrarse en analizar los presupuestos que arrogó para sí la filosofía moderna. Para él, el conocimiento como representación y la verdad como correspondencia han sido 
dos concepciones que han estado a la base de la invención y desarrollo de la propia filosofía. Rorty se propone dar una nueva «imagen» de la filosofía que esté libre de las suposiciones modernas. El acierto del pensador americano comienza por haber mostrado una profunda comprensión de las razones que han hecho que la epistemología y su historia transcurriesen de un modo y no de otro; de las razones por las que se ha enfrentado a unos problemas y no a otros.

2. La referencia a Nietzsche resultaba pertinente por cuanto este autor ha sido situado como uno de los grandes inspiradores de la revuelta contra la «filosofía» (entendida, en este contexto, como «platonismo»), revuelta en la que Derrida y después Rorty han jugado un papel crucial. Si bien el método seguido por Rorty a la hora de mostrar la frágil estructura de los «problemas» epistemológicos parece contener mayor radicalidad que el de Derrida, ambos obtuvieron conclusiones que los asemeja en extremo. Esto nos permite percibir la influencia de la crítica nietzscheana a la teoría del conocimiento.

3. El concepto «deconstrucción» es parte de la novedad que Derrida aportó a la filosofía del siglo XX. También ha sido objeto de estudio por parte de Rorty. Sería oportuno analizar si es posible recurrir a él (e incorporar lo que conlleva) para calificar el gesto que el propio Rorty ha llevado a cabo con la epistemología. Si algunas obras recientes han hecho uso del término heideggeriano «destrucción» para referirse a la «superación» de la teoría del conocimiento, lo relevante en nuestro caso provendría de la vinculación que podríamos establecer entre «superación» y «deconstrucción», a través de ese otro concepto, «destrucción». No nos referimos a una mera equiparación de los términos. Todos ellos, con sus connotaciones propias, sirven para calificar fenómenos que tienen algo en común. Lo interesante para nuestro contexto no es solo que vendrían a estar dentro de un «aire de familia» (el cual Rorty ha visto, por ejemplo, entre la hermenéutica y la filosofía postanalítica), sino, sobre todo, el hecho de que representen tareas que el propio filósofo norteamericano ha circunscrito dentro de un mismo sentir filosófico. Él da por descontado que el significado que Heidegger da en Ser y tiempo 
(en concreto, en el parágrafo VI) al concepto «destrucción» difiere de la «diseminación» derridiana, sin embargo el concepto que utiliza para calificar lo que ha de hacerse con la historia de la metafísica («superar», überwinden) se enmarca dentro de lo que Rorty ha calificado como «filosofía edificante».

4. Hemos tratado de caracterizar, con base en las ideas de Rorty, el pensamiento de Derrida respondiendo negativamente a la pregunta sobre si su pensamiento cabe ser calificado como «trascendental». Derrida no es uno de los filósofos fundamentales a partir de los cuales Rorty extrae y desarrolla las ideas básicas que han determinado la importancia de La filosofía y el espejo de la naturaleza. No obstante, según hemos visto aquí, tanto el filósofo francés como su maestro Nietzsche han contribuido sumamente a arraigar dentro de la propia filosofía la necesidad de superar la teoría del conocimiento.

\section{Bibliografía}

Apel, Karl-Otto. La trasformación de la filosofía II. Madrid: Taurus, 1986.

Bermudo, José Manuel. Filosofía política III: asaltos a la razón política. Barcelona: El Serbal, 2005.

Carnap, Rudolf. «Superación de la metafísica mediante el análisis lógico del lenguaje». En El positivismo lógico. Editado por Alfred J. Ayer. Madrid: FCE, 1993.

Davidson, Donald. De la verdad y de la interpretación. Barcelona: Gedisa 1990.

. «De la idea misma de un esquema conceptual». Proceedings of the American Philosphical Association 47 (1973): 5-20

. «Truth and meaning». Synthese 17 (1967): 304-323.

De Peretti, Cristina. Jacques Derrida. Texto y Deconstrucción. Barcelona: Anthropos, 1989. 
. «Deconstrucción». En Diccionario de hermenéutica. Editado por Andrés Ortiz-Osés y Patxi Lanceros. Bilbao: Universidad de Deusto, 1998.

Derrida, Jacques. De la gramatología. Madrid: Siglo XXI, 1986.

. Márgenes de la filosofía. Madrid: Cátedra, 1998.

. La voz y el fenómeno. Valencia: Pre-textos, 1985.

. La Diseminación. Madrid: Fundamentos, 1975.

. Espolones. Los estilos de Nietzsche. Valencia: Pre-textos, 1981.

Gettier, Edmund. «Is Justified True Belief Knowledge?». Analysis 23 (1963): 121-123.

Heidegger, Martin. Caminos del bosque. Madrid: Alianza, 1996.

Horkheimer, Marx. Crítica de la razón instrumental. Madrid: Trotta, 2002.

Horwich, Paul. «Rorty's Wittgenstein». En Wittgenstein's Philosophical Investigations. 145-161. Editado por Arif Ahmed. Cambridge: Cambridge University Press, 2010.

Kalpokas, Daniel. Richard Rorty y la superación pragmatista de la epistemología. Buenos Aires: Del Signo, 2005.

Maraguat, Edgar. «Apercepción y sistemas causales. A vueltas con la filosofía kantiana de la mente». Ágora 26-1 (2007): 79-98.

Nájera, Elena. «El contexto del debate contemporáneo en torno a la superación/recuperación de la epistemología». Daimon. Revista Internacional de Filosofía 51 (2010): 183-198.

Nietzsche, Friedrich W. Crepúsculo de los ídolos. Madrid: Alianza, 1998.

Orbán, Jolán. «Pragrammatology: Derrida's Pragmatism, Rorty's Deconstruction». En The Philosophy of Richard Rorty. Editado por Randall E. Auxier y Lewis E. Hahn. Chicago: Open Court. 2010.

Penelas, Federico. «Recepciones pragmatistas de Martin Heidegger». Areté 23-1 (2011): 109-124. 
Platón. Teeteto. Madrid: Biblioteca nueva, 2008.

Popper, Karl. Conocimiento objetivo. Madrid: Tecnos, 2010.

Rorty, Richard. La filosofía y el espejo de la naturaleza. Madrid: Cátedra, 2010.

. Consecuencias del pragmatismo. Madrid: Tecnos, 1996.

. Contingencia, ironía y solidaridad. Barcelona: Paidós, 1991.

. Ensayos sobre Heidegger y otros filósofos contemporáneos.

Escritos filosóficos II. Barcelona: Paidós, 1993.

. Filosofía y futuro. Barcelona: Gedisa, 2008.

. «Notas sobre deconstrucción y pragmatismo». En Deconstrucción y pragmatismo. Editado por Chantal Mouffe. Buenos Aires: Paidós, 1998.

. «Reply to Jolán Orbán». En The Philosophy of Richard Rorty. Editado por Randall E. Auxier y Lewis E. Hahn. Chicago: Open Court. 2010.

Sanfélix, Vicente. Mente y conocimiento. Madrid: Biblioteca Nueva, 2003.

Sellars, Wilfrid. Ciencia, percepción y realidad. Madrid: Tecnos, 1971.

Taylor, Charles. Argumentos filosóficos. Barcelona: Paidós, 1997.

Vidarte, Francisco y Rampérez, Francisco. Filosofías del siglo XX. Madrid: Síntesis, 2005.

Wheeler, Samuel. «Davidson as Derridean: Analytic Philosophy as Deconstruction». Cardozo Law Review 27-2 (2005): 567-585.

Zarzo Durá, María E. «Jacques Derrida: ontología y lingüística». Cuaderno de materiales. Filosofía y ciencias humanas 23 (2011): 781-811. 